\title{
Article
}

\section{Therapeutic Drug Monitoring of Carbamazepine: A 20-Year Observational Study}

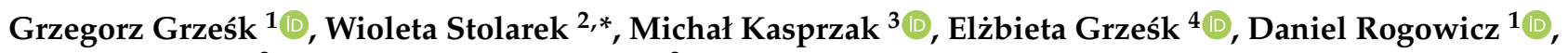 \\ Michał Wiciński ${ }^{2}$ and Marek Krzyżanowski ${ }^{2}$
}

1 Department of Cardiology and Clinical Pharmacology, Faculty of Health Sciences, Collegium Medicum, Nicolaus Copernicus University, Skłodowskiej-Curie 9, 85-094 Bydgoszcz, Poland; ggrzesk@cm.umk.pl (G.G.); rogowicz.d@gmail.com (D.R.)

2 Department of Pharmacology and Therapeutics, Faculty of Medicine, Collegium Medicum, Nicolaus Copernicus University, Skłodowskiej-Curie 9, 85-094 Bydgoszcz, Poland; wicinski4@wp.pl (M.W.); marekwjk@cm.umk.pl (M.K.)

3 Department of Cardiology and Internal Diseases, Faculty of Medicine, Collegium Medicum, Nicolaus Copernicus University, Skłodowskiej-Curie 9, 85-094 Bydgoszcz, Poland; medkas@o2.pl

4 Department of Pediatrics, Hematology and Oncology, Faculty of Medicine, Collegium Medicum, Nicolaus Copernicus University, Skłodowskiej-Curie 9, 85-094 Bydgoszcz, Poland; ellag@cm.umk.pl

* Correspondence: wioletaplazuk@o2.pl; Tel./Fax: +48-52-585-35-84

Citation: Grześk, G.; Stolarek, W.; Kasprzak, M.; Grześk, E.; Rogowicz, D.; Wiciński, M.; Krzyżanowski, M. Therapeutic Drug Monitoring of Carbamazepine: A 20-Year Observational Study. J. Clin. Med. 2021, 10, 5396. https://doi.org/ $10.3390 / \mathrm{jcm} 10225396$

Academic Editor: Umberto Aguglia

Received: 24 October 2021

Accepted: 15 November 2021

Published: 19 November 2021

Publisher's Note: MDPI stays neutral with regard to jurisdictional claims in published maps and institutional affiliations.

Copyright: (c) 2021 by the authors. Licensee MDPI, Basel, Switzerland. This article is an open access article distributed under the terms and conditions of the Creative Commons Attribution (CC BY) license (https:// creativecommons.org/licenses/by/ $4.0 /)$.

\begin{abstract}
Background: Carbamazepine (CBZ) is a first-generation anticonvulsant drug. Hence, in certain cases, therapeutic drug monitoring (TDM) supports pharmacotherapy. Methods: The presented research was based on a retrospective analysis including 710 ambulatory and hospitalized patients treated with CBZ between the years 1991 and 2011. The method used for the determination of the CBZ concentration was fluorescence polarization immunoassay (FPIA) performed using an Abbott GmbH TDx automatic analyzer, with the therapeutic range for carbamazepine being 4-12 $\mu \mathrm{g} / \mathrm{mL}$. Results: The therapeutic range was observed more often in patients between 3 and 17 years of age compared with the population $\geq 18$ years of age $(73.5 \%$ vs. $68.8 \%)$. The therapeutic level was exceeded less frequently in the population between 3 and 17 years of age despite them being given a significantly higher dose per kilogram of body weight than in the population $\geq 18$ years of age $(13.64 \mathrm{mg} / \mathrm{kg}$ vs. $10.43 \mathrm{mg} / \mathrm{kg}, p<0.0001)$. Patients $\geq 18$ years of age were statistically significantly more likely to be in the group with a suspected drug overdose (73.9\% vs. $26.1 \%)$, and suicide attempts only occurred in elderly patients $(100.0 \%$ vs. $0.0 \%, p=0.003)$. Conclusion: The results of the TDM of CBZ showed that only $71 \%$ of all samples were at the therapeutic level. To ensure the maximum efficacy and safety of the therapy, it is necessary to monitor the concentration of CBZ regardless of sex and age.
\end{abstract}

Keywords: carbamazepine; antiepileptic drugs; carbamazepine plasma levels; epilepsy; therapeutic drug monitoring

\section{Introduction}

Carbamazepine (CBZ), one of the classic antiepileptic drugs (AEDs), was introduced in the 1960s and 1970s. It still plays a dominant role in epilepsy treatment as the first-line drug of choice (DOC), especially for different focal epileptic syndromes [1-3]. In addition, this drug is used, among other things, to treat idiopathic neuralgias of the trigeminal and glossopharyngeal nerves and pain caused by diabetic neuropathy. Carbamazepine blocks voltage-gated sodium channels, thus stabilizing the cell membranes of nerve fibers, inhibiting neuronal discharge, and reducing excitatory synaptic transmission [4]. Pharmacokinetics in patients above 3 years of age are comparable to those in adults [5]. The dosage of CBZ for epilepsy in adults is 0.8-1.2 g/day 2-3 times a day. However, in children from 1 to 15 years of age, it amounts to $0.1-1 \mathrm{~g} /$ day (10-25 mg/ $\mathrm{kg} /$ day) [6]. CBZ is a drug 
with a strong effect on metabolic processes that may cause clinically significant drug interactions.CBZ induces CYP3A4 and CYP1A2 isoenzymes, thus reducing the concentration of other drugs (e.g., DSA). CBZ is metabolized by CYP1A2, CYP3A4, CYP2C8, and CYP2C9 isoenzymes, and itself is also subject to interactions changing its serum concentration. The increase in CBZ concentration is caused by, inter alia, clarithromycin and erythromycin, while the reduction in CBZ concentration is caused by, among other things, phenobarbital and rifampicin [4]. Therapeutic drug monitoring (TDM) is recommended for the rapiesusing antiepileptic drugs, including CBZ. The posology can be optimized by TDM due to the good correlation between the plasmatic concentration and the therapeutic effect [6]. The test should be ordered individually in particular situations (e.g., in the case of drug interactions, for suspected drug poisoning, or for monitoring compliance with medical recommendations) [1,7]. It has been shown that the use of TDM in epilepsy treatment can improve seizure control and minimize the risk of side effects as well as limiting polytherapy, thus reducing treatment costs [8]. It should be remembered that drug side effects do not have to be associated with a high drug concentration in the plasma. On the other hand, the symptoms of poisoning can be misinterpreted as the symptoms of a primary disease of the nervous system.

Epilepsy is the most common neurological disease, with a prevalence ranging from $0.5 \%$ to $1 \%$ in developed countries [9]. Convulsions arise as a result of an imbalance between the excitatory and inhibitory systems in the central nervous system. The etiology of epilepsy is not fully understood (it may be the result of, among other things, perinatal trauma, infections of the central nervous system, head injury, and brain tumors) [10]. In order to effectively treat epilepsy, it is necessary to correctly diagnose the disease and introduce appropriate treatment. In approximately $70 \%$ of patients, monotherapy is the primary treatment method and allows full seizure control. The choice of an antiepileptic drug depends on the individual patient's characteristics. The facts that should be taken into consideration here are the type of epilepsy, the patient's age, the existence of comorbidities, and the possible drug interactions [11].

\section{Materials and Methods}

\subsection{Patients}

A CBZ level assessment was performed in the Department of Pharmacology and Therapy in patients from the Kuyavian-Pomeranian Voivodeship between the years 1991 and 2011. The trial was designed as a retrospective analysis and included 710 ambulatory and hospitalized patients. The determination of the CBZ level was most often combined with consultation with a clinical pharmacologist. At that time, it was the only such center in the region that measured the concentration of both antiepileptic (CBZ, valproic acid, phenytoin) and other drugs, e.g., digoxin [12]. Moreover, it was also the only center in the voivodeship that measured the concentration of novel oral anticoagulants (NOACs) in the following years [13]. The study population took carbamazepine in the form of oral tablets.

\subsection{Procedures}

For all patients, the carbamazepine concentration in the blood serum (without anticoagulants) taken during hospitalization was determined. Fluorescence polarization immunoassay (FPIA) performed by an Abbott GmbH TDx automatic analyzer was used to determine the CBZ serum concentration. The limit of detection was $0.005 \mu \mathrm{g} / \mathrm{mL}$. The therapeutic range for carbamazepine was established as $4-12 \mu \mathrm{g} / \mathrm{mL}$ according to the manufacturer's requirements.

\subsection{Statistics}

The Polish version of the statistical software Statistica 12.0 (StatSoft, Tulsa, OK, USA) was used to calculate statistical parameters. The Shapiro-Wilk test assay revealed that the distribution of continuous variables did not meet the criteria of a normal distribution. As a result, quantitative variables were shown as medians and quartile ranges. To compare the 
medians of independent variables, the Mann-Whitney test, the Kruskal-Wallis test, and the multiple comparison test were performed. Qualitative variables were presented as the number of patients with a particular feature and as the percentage of the analyzed group. Comparison between qualitative variables was performed using $\chi^{2}$. Values of $p<0.05$ were treated as statistically significant. Values of $p \geq 0.05$ and $<0.10$ were treated as a trend towards statistical significance. Values of $p \geq 0.10$, which were treated as not significant, were replaced with the abbreviation $n s$ (not significant).

\section{Results}

In total, 710 cases were analyzed, including 339 men and 371 women. The clinical characteristics of the study population, including the parameters of their CBZ drug therapy, are presented in Table 1 . The average age of the study population was 19, the average height was $168 \mathrm{~cm}$, the average weight was $59 \mathrm{~kg}$, and the average BMI (body mass index) was $22.49 \mathrm{~kg} / \mathrm{m}^{2}$. The most common reason for hospitalization was epilepsy-94.6\%. The average daily carbamazepine intake among the examined patients was $600 \mathrm{mg}$ (in the form of oral tablets). In $3.1 \%$ of cases, it was a single dose; $66.1 \%$ took two daily doses; and $26.9 \%$ took at least three doses per day. The average carbamazepine concentration in the blood serum of the study population was $5.58 \mu \mathrm{g} / \mathrm{mL}$ and remained within the therapeutic range. The therapeutic range was present in $71.0 \%$ of cases. The average time from the beginning of the carbamazepine treatment to the measurement of the carbamazepine concentration in the blood serum was 180 days.

Table 1. Clinical characteristics of the study population (median (lower quartile-upper quartile) or number (percent)).

\begin{tabular}{|c|c|}
\hline Study Feature $(n=710)$ & Property Value \\
\hline Age & $19.0(11.0-31.0)$ \\
\hline 3-17 (years) & $332(46.8 \%)$ \\
\hline$\geq 18$ (years) & $378(53.2 \%)$ \\
\hline$\overline{\text { Height }(\mathrm{cm})}$ & $168.0(160.0-175.0)$ \\
\hline Body weight $(\mathrm{kg})$ & $59.0(35.0-70.0)$ \\
\hline $\mathrm{BMI}\left(\mathrm{kg} / \mathrm{m}^{2}\right)$ & $22.49(19.59-25.35)$ \\
\hline \multicolumn{2}{|l|}{ Sex } \\
\hline Men & $339(47.7 \%)$ \\
\hline Women & $371(52.3 \%)$ \\
\hline \multicolumn{2}{|l|}{ The main reason for hospitalization } \\
\hline Epilepsy & $672(94.6 \%)$ \\
\hline Suspected drug overdose & $23(3.2 \%)$ \\
\hline Suicide attempt & $8(1.1 \%)$ \\
\hline Not specified & $7(1.0 \%)$ \\
\hline The daily dose of carbamazepine (mg) * & $600.0(400.0-800.0)$ \\
\hline The daily dose of carbamazepine per kilogram of body weight $(\mathrm{mg})$ * & $12.00(9.09-15.79)$ \\
\hline \multicolumn{2}{|l|}{ The number of doses per day } \\
\hline 1 & $22(3.1 \%)$ \\
\hline 2 & $469(66.1 \%)$ \\
\hline$\geq 3$ & $191(26.9 \%)$ \\
\hline No data (including patients with suicide attempt) & $28(3.9 \%)$ \\
\hline Carbamazepine concentration $(\mu \mathrm{g} / \mathrm{mL})$ & $5.58(4.01-7.33)$ \\
\hline Time period from the beginning of treatment with carbamazepine (days) & $180.0(60.0-700.0)$ \\
\hline $\begin{array}{l}\text { Carbamazepine below the therapeutic level } \\
\qquad(<4 \mu \mathrm{g} / \mathrm{mL})\end{array}$ & $177(24.9 \%)$ \\
\hline $\begin{array}{l}\text { The therapeutic level of carbamazepine } \\
\qquad(4-12 \mu \mathrm{g} / \mathrm{mL})\end{array}$ & $504(71.0 \%)$ \\
\hline $\begin{array}{l}\text { Carbamazepine above therapeutic level } \\
\qquad(\geq 12 \mu \mathrm{g} / \mathrm{mL})\end{array}$ & $29(4.1 \%)$ \\
\hline
\end{tabular}


An analysis of the study population showed statistically significant differences between the carbamazepine concentration depending on the main reason for hospitalization (Table 2, Figure 1). A statistically significant correlation was demonstrated between epilepsy and suicide attempt $(p<0.001)$ and between suspected drug overdose and suicide attempt $(p=0.005)$. The average concentration of carbamazepine in patients with epilepsy was $5.52 \mu \mathrm{g} / \mathrm{mL}$. In this group of patients, a concentration below the therapeutic range $(<4 \mu \mathrm{g} / \mathrm{mL})$ was observed in 167 patients $(24.9 \%)$, a concentration at the therapeutic level (4-12 $\mu \mathrm{g} / \mathrm{mL})$ was found in 491 patients $(73.1 \%)$, and a concentration in the range above the therapeutic level $(\geq 12 \mu \mathrm{g} / \mathrm{mL})$ was found in 14 patients $(2.1 \%)$. Among patients with a suspected drug overdose, the median drug concentration was $7.24 \mu \mathrm{g} / \mathrm{mL}$. In these patients, concentrations below the therapeutic range were found in 6 patients $(26.1 \%)$, concentrations at the therapeutic level were observed in 10 (43.5\%), and in 7 patients (30.4\%) the therapeutic range was exceeded. In the case of patients who made a suicide attempt, the average concentration of carbamazepine was $21.0 \mu \mathrm{g} / \mathrm{mL}$. In all these patients, only a CBZ concentration above the therapeutic range was recorded. In the study population (excluding patients with no dose data and who made a suicide attempt), regardless of the number of doses taken per day, the median concentration of CBZ was within the therapeutic range and did not differ statistically (Table 2). Among patients taking carbamazepine once daily, only $45.5 \%$ were within the therapeutic concentration range. In patients receiving the drug twice daily or more, the therapeutic concentration range was seen statistically significantly more frequently $-72.5 \%$ and $75 \%(p=0.035)$, respectively. There were no statistically significant differences in the measured drug level according to sex and age (Table 2).

Table 2. Carbamazepine concentration in the study population depending on selected clinical parameters (median (lower quartile-upper quartile) or number [percent]).

\begin{tabular}{ccc}
\hline Study Feature & $\begin{array}{c}\text { Carbamazepine } \\
\text { Concentration }(\mu \mathrm{g} / \mathbf{m L})\end{array}$ & $p$ \\
\hline The main reason for hospitalization $(n=703)$ & $5.52(4.01-7.22)$ & $<0.0001$ \\
$\quad$ Epilepsy & $7.24(3.08-12.61)$ & \\
Suspected drug overdose & $21.0(19.67-22.63)$ & \\
Suicide attempt & & \\
Sex $(n=710)$ & $5.52(4.01-7.24)$ & \\
Women & $5.63(3.88-7.40)$ & \\
Men & & \\
Age (years) $(n=710)$ & $5.50(4.07-7.14)$ & \\
$3-17$ & $5.76(3.92-7.54)$ & \\
$\geq 18$ & & \\
The number of doses per day $(n=682)$ & $5.03(3.0-6.48)$ & \\
1 & $5.70(3.98-7.26)$ & \\
2 & $5.36(4.14-7.23)$ & \\
\hline
\end{tabular}

In the study population (excluding patients with no dose data and who made a suicide attempt), statistically significant differences were found between the daily dose and the daily dose of carbamazepine per kilogram of body weight depending on the patients' age (Table 3, Figure 2). The average daily dose of carbamazepine in patients between 3 and 17 years of age amounted to $450 \mathrm{mg}$ (daily dose per kilogram of body weight-13.64 mg). However, in patients $\geq 18$ years of age it was $800 \mathrm{mg}$ and $10.43 \mathrm{mg} / \mathrm{kg}$ bw $(p<0.00001)$, respectively. There were also statistically significant differences between the daily dose of carbamazepine and the level of CBZ. A statistically significant difference was demonstrated between the level below the therapeutic range and the therapeutic level $(p<0.001)$, and between the level below and above the therapeutic level $(p<0.001)$. A trend towards statistical significance $(p=0.081)$ was also demonstrated between the therapeutic level and the level above the therapeutic window (Table 3). On average, the daily dose amounted to $400 \mathrm{mg}$ in patients with a CBZ concentration below the therapeutic level, $600 \mathrm{mg}$ in 
patients at the therapeutic level, and $850 \mathrm{mg}$ in patients with levels above the therapeutic range. Statistically significant differences were also found between the daily dose of carbamazepine per kilogram of body weight and the CBZ level. Statistically significant differences were demonstrated between the level below the therapeutic range and the therapeutic level $(p<0.001)$. On average, in patients with CBZ concentrations below the therapeutic level, the daily dose per kilogram of body weight amounted to $9.92 \mathrm{mg}$; in patients with levels at the therapeutic level it was $12.86 \mathrm{mg}$; and in patients with levels above the therapeutic range it was $12.50 \mathrm{mg}$. The average daily dose of CBZ was $600 \mathrm{mg}$ for both men and women. The average dose per kilogram of body weight was $11.43 \mathrm{mg}$ in men and $12.1 \mathrm{mg}$ in women. These results were not statistically significant.

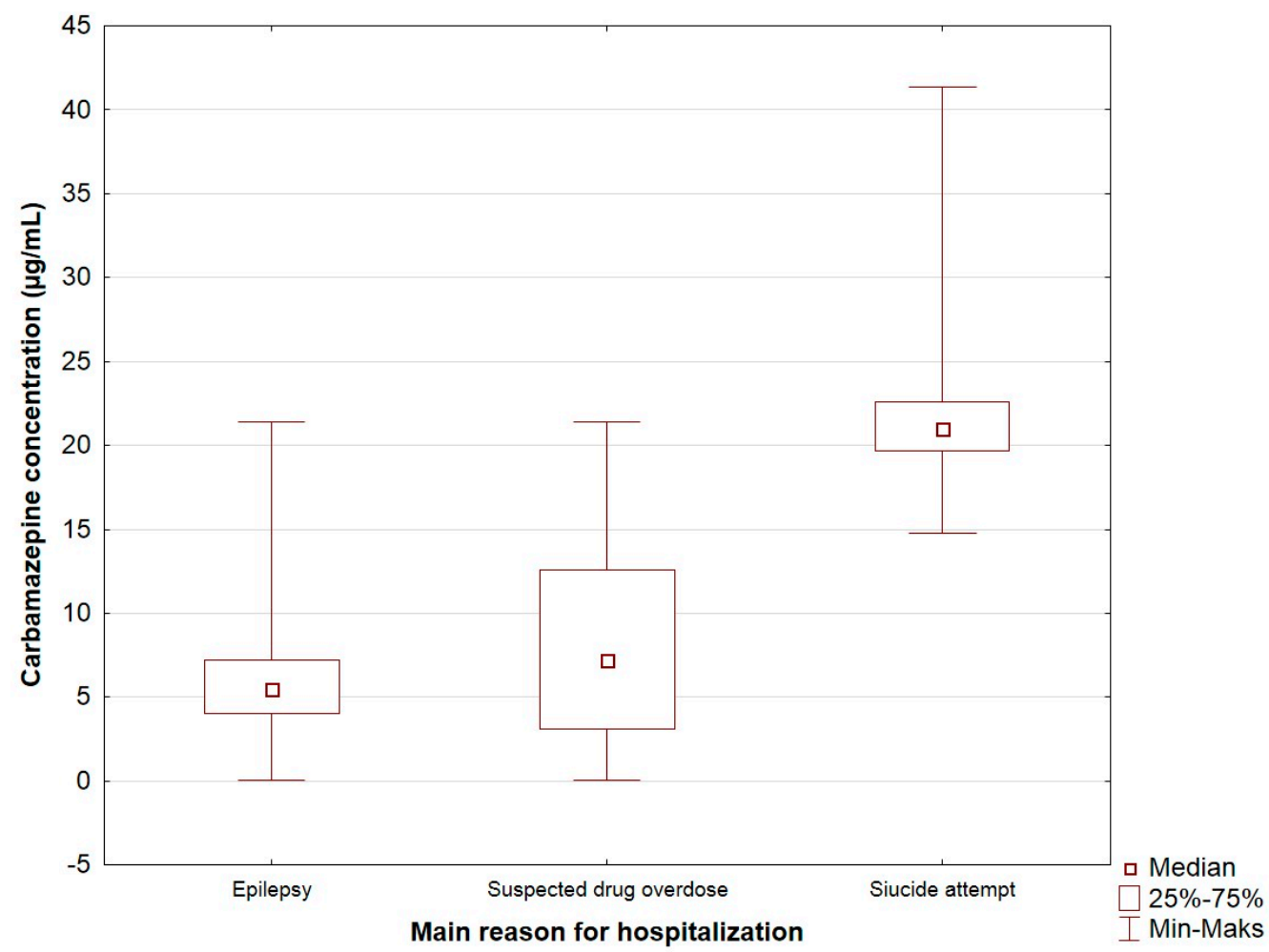

Figure 1. The carbamazepine concentration $(\mu \mathrm{g} / \mathrm{mL})$ depending on the main reason for hospitalization (marker-median; edges of the box-upper and lower quartile; whiskers—range of nonoutlier values).

Table 3. Pharmacotherapy with carbamazepine in the study population depending on selected clinical parameters (median (lower quartile-upper quartile) or number (percent)).

\begin{tabular}{cccc}
\hline $\begin{array}{c}\text { Study Feature } \\
(\boldsymbol{n}=\mathbf{6 8 2})\end{array}$ & $\begin{array}{c}\text { The Daily Dose of } \\
\text { Carbamazepine }(\mathbf{m g})\end{array}$ & $\boldsymbol{p}$ & $\begin{array}{c}\text { The Daily Dose of Carbamazepine Per } \\
\text { Kilogram of Body Weight (mg) }\end{array}$ \\
Sex & $600(400-800)$ & 0.3593 & $11.43(8.57-15.38)$ \\
Men & $600(400-800)$ & & $12.1(9.52-16.0)$ \\
Women & $450(300-600)$ & $<0.00001$ & $13.64(10.26-17.86)$ \\
Age & $800(600-900)$ & & $10.43(8.00-13.33)$ \\
\hline-17 (years) & (years) & & $<0.0891$ \\
\hline
\end{tabular}


Table 3. Cont.

\begin{tabular}{|c|c|c|c|c|}
\hline $\begin{array}{l}\text { Study Feature } \\
\quad(n=682)\end{array}$ & $\begin{array}{l}\text { The Daily Dose of } \\
\text { Carbamazepine (mg) }\end{array}$ & $p$ & $\begin{array}{c}\text { The Daily Dose of Carbamazepine Per } \\
\text { Kilogram of Body Weight (mg) }\end{array}$ & $p$ \\
\hline $\begin{array}{l}\text { Carbamazepine below the } \\
\text { therapeutic level } \\
(<4 \mu \mathrm{g} / \mathrm{mL})\end{array}$ & $400(300-600)$ & & $9.92(6.78-12.50)$ & \\
\hline $\begin{array}{l}\text { The therapeutic level of } \\
\text { carbamazepine } \\
(4-12 \mu \mathrm{g} / \mathrm{mL})\end{array}$ & $600(450-800)$ & $<0.00001$ & $12.86(9.68-16.67)$ & $<0.00001$ \\
\hline $\begin{array}{l}\text { Carbamazepine above the } \\
\text { therapeutic level } \\
(\geq 12 \mu \mathrm{g} / \mathrm{mL})\end{array}$ & $850(600-1000)$ & & $12.50(10.0-18.46)$ & \\
\hline
\end{tabular}

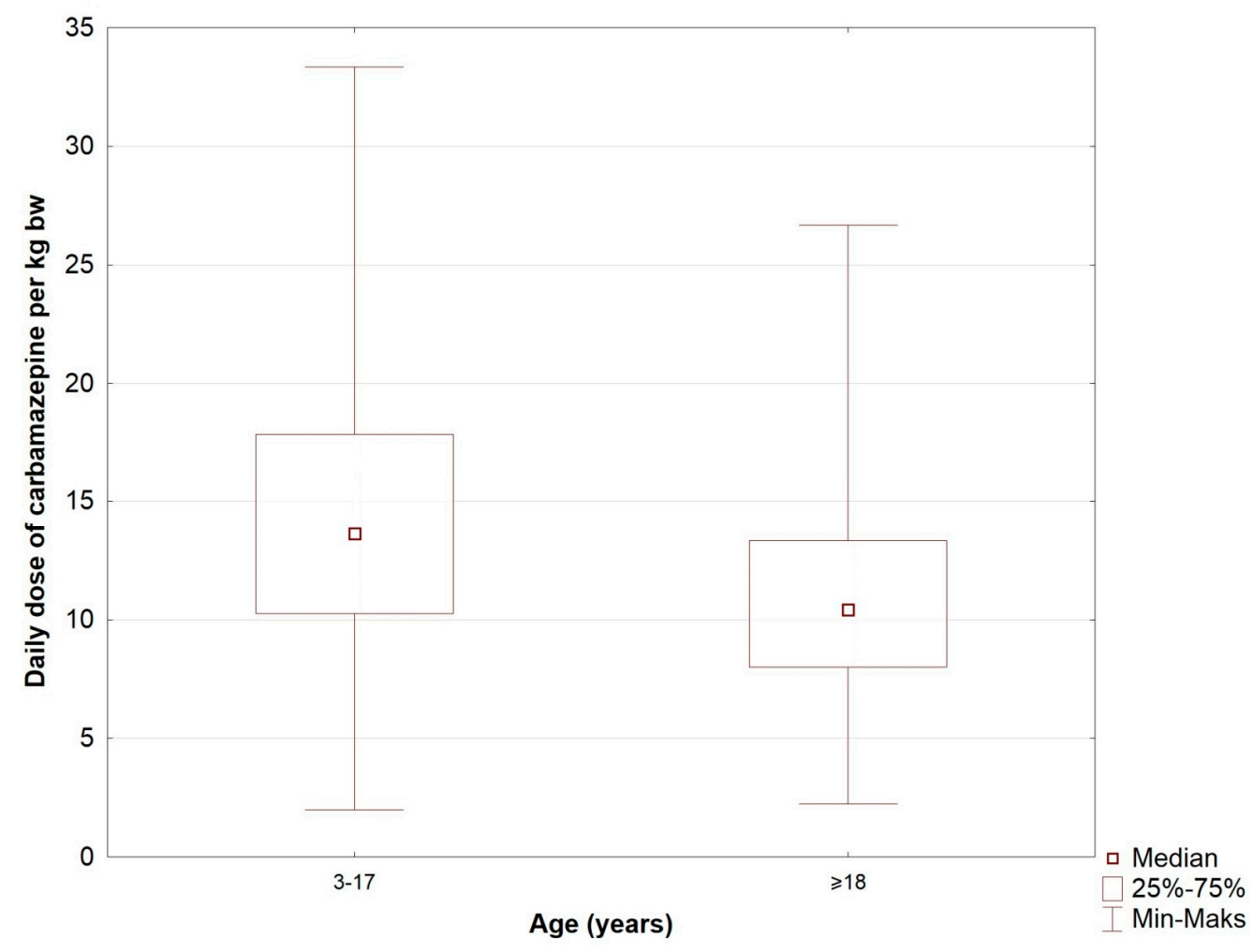

Figure 2. Daily dose of CBZ (mg) depending on age in the study population (marker-median; edges of the box-upper and lower quartile; whiskers—range of non-outlier values).

In the study population (excluding patients with no dose data and who made a suicide attempt), statistically significant differences were found depending on the main reason for hospitalization and age $(p=0.003)$ (Table 4$)$. In both age groups (3-17 and $\geq 18$ years old), epilepsy was the dominant cause of hospitalization. In addition, there was a higher proportion of elderly patients with a suspected drug overdose and a suicide attempt. In terms of gender, epilepsy was also the main reason for hospitalization. There was a higher proportion of women with a suspected drug overdose and a much higher proportion of men with a suicide attempt, although the observed differences did not reach statistical significance. Statistically significant differences were found depending on age and the number of doses of the drug taken per day $(p=0.0100)$. Patients from both age groups most often took CBZ twice a day (among patients between 3 and 17 years of age the percentage was $73.3 \%$, and after the age of 18 years it amounted to $64.7 \%$ ). Younger people were more often treated with one dose a day (4.0\% vs. $2.5 \%)$ but less frequently with at least 3 doses a day (22.7\% vs. $32.8 \%$ ). No statistically significant differences were found depending on sex and the number of doses taken per day. In the female population of the 
study group, there was a slightly higher frequency of patients reaching the therapeutic ranges $(72.2 \%$ vs. $69.6 \%)$ and a lower frequency of patients exceeding the therapeutic $(3.2 \%$ vs. $5.0 \%)$ and subtherapeutic levels $(24.5 \%$ vs. $25.4 \%)$ than in the male population. However, these differences were not statistically significant. Additionally, the therapeutic range was more often observed in patients aged 3-17 years (73.5\% vs. $68.8 \%)$ compared with the population $\geq 18$ years of age, whereas the subtherapeutic levels were reached slightly less frequently $(24.1 \%$ vs. $25.7 \%)$. On the other hand, the therapeutic level was exceeded over twice less frequently ( $2.4 \%$ vs. $5.6 \%)$. The obtained differences were close to statistical significance $(p=0.0082)$.

Table 4. Daily carbamazepine dose and the main reason for hospitalization of the study population depending on age and sex (median (lower quartile-upper quartile) or number (percent)).

\begin{tabular}{|c|c|c|c|c|c|c|}
\hline \multirow{2}{*}{ Study Feature } & \multicolumn{2}{|c|}{ Sex } & \multirow{2}{*}{$p$} & \multicolumn{2}{|c|}{ Age (years) } & \multirow{2}{*}{$p$} \\
\hline & Men & Women & & 3-17 & $\geq 18$ & \\
\hline \multicolumn{7}{|c|}{ The main reason for hospitalization $(n=703)$} \\
\hline Epilepsy & $320(47.6 \%)$ & $352(52.4 \%)$ & & $325(48.4 \%)$ & $347(51.6 \%)$ & \\
\hline Suspected drug overdose & $9(39.1 \%)$ & $14(60.9 \%)$ & 0.056 & $6(26.1 \%)$ & $17(73.9 \%)$ & 0.003 \\
\hline Suicide attempt & $7(87.5 \%)$ & $1(12.5 \%)$ & & $0(0.00 \%)$ & $8(100 \%)$ & \\
\hline \multicolumn{7}{|c|}{ The number of doses per day $(n=682)$} \\
\hline 1 & $14(63.6 \%)$ & $8(36.4 \%)$ & & $13(4.0 \%)$ & $9(2.5 \%)$ & \\
\hline 2 & $213(45.4 \%)$ & $256(54.6 \%)$ & 0.139 & $236(73.3 \%)$ & $233(64.7 \%)$ & 0.0100 \\
\hline$\geq 3$ & $97(50.8 \%)$ & $94(49.2 \%)$ & & $73(22.7 \%)$ & $118(32.8 \%)$ & \\
\hline \multicolumn{7}{|c|}{ Carbamazepine concentration $(\mu \mathrm{g} / \mathrm{mL})$} \\
\hline $\begin{array}{l}\text { Carbamazepine below the } \\
\text { therapeutic level }(<4 \mu \mathrm{g} / \mathrm{mL})\end{array}$ & $86(25.4 \%)$ & $91(24.5 \%)$ & & $80(24.1 \%)$ & $97(25.7 \%)$ & \\
\hline $\begin{array}{l}\text { The therapeutic level of } \\
\text { carbamazepine }(4-12 \mu \mathrm{g} / \mathrm{mL})\end{array}$ & $236(69.6 \%)$ & $268(72.2 \%)$ & 0.4502 & $244(73.5 \%)$ & $260(68.8 \%)$ & 0.0082 \\
\hline $\begin{array}{l}\text { Carbamazepine above the } \\
\text { therapeutic level }(\geq 12 \mu \mathrm{g} / \mathrm{mL})\end{array}$ & $17(5.0 \%)$ & $12(3.2 \%)$ & & $8.0(2.4 \%)$ & $21.0(5.6 \%)$ & \\
\hline
\end{tabular}

\section{Study Limitations}

Several limitations of our study merit consideration-primarily, the incomplete data for the study population resulting mainly from the large number of subjects and the duration of the follow-up. Unfortunately, they were not included in the electronic database. Moreover, there was no information about potential pregnancy, additional pharmacotherapy, or comorbidities that affected the level of CBZ. In addition, it was not possible to verify the compliance declared by the patient.

\section{Discussion}

Carbamazepine is a first-generation anticonvulsant drug recommended for use in the treatment of focal epilepsy [1]. The main effect of the drug is to stabilize the cell membranes of nerve fibers, inhibit neuronal discharges, and reduce excitatory synaptic transmission [4]. In some clinical situations, however, the risk of significant drug interactions is a major limitation affecting the use of CBZ [4]. In the study population, the determination of the CBZ level was most often combined with consultation with a clinical pharmacologist. Therefore, TDM supports pharmacotherapy in certain cases. In our study, $71 \%$ of patients taking CBZ had drug concentrations at the therapeutic level. These results are slightly lower than those obtained by Shakya et al. [14], who reported that $79.3 \%$ of patients in a similar population also possessed therapeutic levels of CBZ. On the other hand, $24.9 \%$ of the studied population had concentrations below the therapeutic level, which could be related, for instance, to noncompliance with the medical recommendations or the use of other drugs that reduced the concentration of CBZ. Compliance can be improved by 
reducing the number of daily doses and the routine monitoring of the drug levels. In the study population, patients aged 3-17 years reached the therapeutic range more often $(73.5 \%$ vs. $68.8 \%)$ compared to the population $\geq 18$ years of age, whereas the subtherapeutic levels were observed slightly less frequently $(24.1 \%$ vs. $25.7 \%)$. The obtained results are very important because, according to other studies, this age group has a higher risk of noncompliance with medical recommendations, which is the reason for the low plasma concentrations of CBZ [15-17]. In the study by Specht et al., a drop in serum levels $>50 \%$, indicating medication noncompliance, was noted in $44.3 \%$ of the seizures in young adults with epilepsy. It is worth noting that the therapeutic level was exceeded less often in the population between 3 and 17 years of age, despite their significantly higher dose per kilogram of body weight than the population $\geq 18$ years $(13.64 \mathrm{mg} / \mathrm{kg}$ vs. $10.43 \mathrm{mg} / \mathrm{kg}$, $p<0.0001)$. These results confirm that in younger age groups there is a faster metabolism of CBZ associated with the approximately $20 \%$ higher activity of the CYP3A4 isoenzyme [18]. Among patients with a suspected drug overdose, patients $\geq 18$ years of age were statistically significantly more frequent $(73.9 \%$ vs. $26.1 \%)$, and suicide attempts were only made by elderly patients $(100.0 \%$ vs. $0.0 \%, p=0.003)$. At the same time, in the population $\geq 18$ years of age, the dose per kilogram of body weight was significantly lower than in the group between 3 and 17 years $(10.43 \mathrm{mg} / \mathrm{kg}$ vs. $13.64 \mathrm{mg} / \mathrm{kg}, p<0.0001)$.

\section{Conclusions}

To sum up, the TDM results of CBZ were evaluated for both sexes in different age groups, where epilepsy was the predominant diagnosis (94.6\%). The TDM results of CBZ showed that only $71 \%$ of all samples were at the therapeutic level (with little variation depending on age, sex, and the number of doses taken per day). In the study population, CBZ was most often taken twice a day (regardless of sex and age), which is in line with current dosing recommendations. The differences in CBZ levels may result from, among other things, different metabolic patterns dependent on sex and age. Pregnancy also affects CBZ concentration because an increased metabolism reduces its concentration. In order to ensure the maximum effectiveness and safety of the therapy, it is necessary to monitor the concentration of CBZ. TDM should be conducted in patients regardless of their sex and age, and the dosage should be adjusted to the results obtained, because the effectiveness of epilepsy treatment is strongly related to the CBZ levels in patients' plasma $[18,19]$.

For the above reasons, from the point of view of a clinical pharmacologist, TDM of CBZ is a standard procedure, similar to, e.g., TDM in digoxin therapy [12], in contrast to a therapy where TDM is available, but due to the high safety of the therapy it can be considered only in selected patients at increased risk of complications or drug interactions [20].

Author Contributions: Conceptualization, G.G., W.S.; Data curation, M.K. (Marek Krzyżanowski), E.G.; Formal analysis, M.K. (Michał Kasprzak); Investigation, W.S., M.W.; Methodology, G.G., M.K. (Marek Krzyżanowski), D.R.; Supervision, M.W.; Validation, M.K. (Michał Kasprzak); Writing-original draft, W.S.; Writing—review and editing, G.G., M.K. (Michał Kasprzak), E.G., M.W. All authors have read and agreed to the published version of the manuscript.

Funding: This research received no external funding.

Institutional Review Board Statement: Not applicable.

Informed Consent Statement: Not applicable.

Data Availability Statement: The study data may be available on request.

Conflicts of Interest: The authors declare no conflict of interest. 


\section{References}

1. National Institute for Health and Clinical Excellence (NICE). The Diagnosis and Management of the Epilepsies in Adults and Children in Primary and Secondary Care; National Institute for Health and Clinical Excellence (NICE): London, UK, 2015.

2. Jedrzejczak, J.; Majkowska-Zwolińska, B.; Ryglewicz, D. Recommendations of the Polish Society of Epileptology regarding the treatment of epileptic seizures in adults. J. Epileptol. 2019, 27, 9-17. [CrossRef]

3. Fisher, R.S.; Cross, J.H.; French, J.A.; Higurashi, N.; Hirsch, E.; Jansen, F.E.; Lagae, L.; Moshe, S.L.; Peltola, J.; Roulet, P.E.; et al. Operational classification of seizure types by the International League Against Epilepsy: Position Paper of the ILAE Commission for Classification and Terminology. Epilepsia 2017, 58, 522-530. [CrossRef] [PubMed]

4. Ochoa, J.G.; Riche, W. Antiepileptic Drugs. Updated 2009. Available online: http:/emedicine.medscape.com//article/1187334overview (accessed on 20 October 2021).

5. Mittag, N.; Meister, S.; Berg, A.M.; Walther, U.I. A Case Report of a Carbamazepine Overdose with Focus on Pharmacokinetic Aspects. Pharmacopsychiatry 2016, 49, 76-78. [CrossRef] [PubMed]

6. Pozzi, M.; Pineschi, R.; Bonanni, P.; Pellegri, A.; Clementi, E. Precipitation of Carbamazepine Controlled Seizures Due to Low-Dose Risperidone in a Child: A Conspiracy to Unbalance Blood Electrolytes. J. Clin. Psychopharmacol. 2016, 36, 729-730. [CrossRef] [PubMed]

7. Patsalos, P.N.; Berry, D.J.; Bourgeois, B.F.; Cloyd, J.C.; Glauser, T.A.; Johannessen, S.I.; Leppik, I.E.; Tomson, T.; Perucca, E. Antiepileptic drugs-best practice guidelines for therapeutic drug monitoring: A position paper by the subcommission on therapeutic drug monitoring, ILAE Commission on Therapeutic Strategies. Epilepsia 2008, 49, 1239-1276. [CrossRef] [PubMed]

8. Bond, C.A.; Raehl, C.L. Clinical and economic outcomes of pharmacist-managed antiepileptic drug therapy. Pharmacotherapy 2006, 26, 1369-1378. [CrossRef] [PubMed]

9. Fisher, R.S.; Acevedo, C.; Arzimanoglou, A.; Bogacz, A.; Cross, J.H.; Elger, C.E.; Engel, J., Jr.; Forsgren, L.; French, J.A. ILAE official report: A practical clinical definition of epilepsy. Epilepsia 2014, 55, 475-482. [CrossRef] [PubMed]

10. Parton, M.; Cockerell, C.O. Epilepsytheaetiology and pathogenesis. Hosp. Pharmacist. 2003, 10, $288-295$.

11. Nadkarni, S.; LaJoie, J.; Devinsky, O. Current treatments of epilepsy. Neurology 2005, 64 (Suppl. 3), S2-S11. [CrossRef] [PubMed]

12. Grześk, G.; Stolarek, W.; Kasprzak, M.; Krzyżanowski, M.; Szadujkis-Szadurska, K.; Wiciński, M.; Grześk, E. Therapeutic drug monitoring of digoxin-20 years of experience. Pharmacol. Rep. 2018, 70, 184-189. [CrossRef] [PubMed]

13. Grześk, G.; Janiszewska, E.; Malinowski, B.; Kubica, A.; Wiciński, M. Adherence in patients with atrial fibrillation treated with dabigatran. Kardiol. Pol. 2018, 76, 1562-1563. [CrossRef] [PubMed]

14. Shakya, G.; Malla, S.; Shakya, K.N.; Shrestha, R. Therapeutic Drug Monitoring of Antiepileptic Drugs. JNMA 2008, 47, 94-97. [CrossRef]

15. Langan, Y.; Sander, J.W.A.S. Sudden Unexpected Death in Patients with Epilepsy Definition, Epidemiology and Therapeutic Implications. CNS Drugs 2000, 13, 337-350. [CrossRef]

16. Gierbolini, J.; Giarratano, M.; Benbadis, S.R. Carbamazepine-related antiepileptic drugs for the treatment of epilepsy-a comparative review. Expert Opin. Pharmacother. 2016, 17, 885-888. [CrossRef] [PubMed]

17. Specht, U.; Elsner, H.; May, T.W.; Schimichowski, B.; Thorbecke, R. Postictal serum levels of antiepileptic drugs for detection of noncompliance. Epilepsy Behav. 2003, 4, 487-495. [CrossRef]

18. Shaikh, A.S.; Guo, R. Measurement and Comparison of Carbamazepine Plasma Levels for Assessment of Compliance, Safety and Toxicity. Ind. J. Pharm. Sci. 2017, 79, 1025-1029. [CrossRef]

19. Burianová, I.; Bořecká, K. Clin Biochem. Routine therapeutic monitoring of the active metabolite of carbamazepine: Is it really necessary? Clin. Biochem. 2015, 48, 866-869. [CrossRef] [PubMed]

20. Grześk, G.; Woźniak-Wiśniewska, A.; Błażejewski, J.; Górny, B.; Wołowiec, Ł.; Rogowicz, D.; Nowaczyk, A. The Interactions of Nintedanib and Oral Anticoagulants-Molecular Mechanisms and Clinical Implications. Int. J. Mol. Sci. 2020, 22, 282. [CrossRef] [PubMed] 